\title{
ВЛИЯНИЕ ПРОБИОТИЧЕСКИХ КОМПЛЕКСОВ НА СТРУКТУРНУЮ ОРГАНИЗАЦИЮ ТКАНЕЙ И ОРГАНОВ КРОЛИКОВ
}

\author{
E.E. Kurchaeva, E.V. Mikhaylov
}

\section{THE INFLUENCE OF PROBIOTIC COMPLEXES ON STRUCTURAL ORGANIZATION OF TISSUES AND ORGANS OF RABBITS}

Курчаева E.E. - канд. техн. наук, доц. кафр. частной зоотехнии Воронежского государственного аграрного университета им. императора Петра I, г. Воронеж.

E-mail: alena.kurchaeva@yandex.ru

Михайлов E.B. - канд. ветеринар. наук, доц. каф. ветеринарно-санитарной экспертизы, эпизоотологии и паразитологии Воронежского государственного аграрного университета им. императора Петра I, г. Воронеж.

E-mail: voronezh81@rambler.ru

Для повышения мясной продуктивности животных находят широкое применение различные пробиотические комплексы, которые оказывают стимулирующее действие на организм животного, а также участвуют в процессах нормализации микробиоценоза кишечника и повышения резистентности организма сельскохозяйственных животных. Цель работы - исследовать влияние пробиотической комплексной добавки на основе «Ветом 3.0» и «Ветом 1.1» на гистологические особенности желудочно-кишечного тракта и длиннейшей мышиы спины молодняка кроликов. Изучено влияние комплексной пробиотической добавки на гистологичесткую структуру органов и тканей молодняка кроликов. Исследования были проведены на помесном поголовье кроликов. Группы формировали из клинически здоровых животных в возрасте 45 суток численностью по 15 голов. Животные первой группы получали основной рацион (комбикорм на основе зерновых культур, жмыха и шрота подслонечного, пшеничных отрубей). Особи второй группы дополнительно к основному рациону получали комплексный пробиотический препарат на основе «Ветом 3.0» и «Ветом 1.1» в дозировке 70 мг/ке массы тела перед утренним кормле-
Kurchaeva E.E. - Cand. Techn. Sci., Assoc. Prof., Chair of Private Zootechnics, Voronezh State Agricultural University named after Emperor Peter I, Voronezh.

E-mail: alena.kurchaeva@yandex.ru

Mikhaylov E.V. - Cand. Veterinary Sci., Assoc. Prof., Chair of Veterinary and Sanitary Examination, Epizootology and Parasitology, Voronezh State Agricultural University named after Emperor Peter I, Voronezh.

E-mail: voronezh81@rambler.ru

нием в течение 10 суток циклом каждые 30 суток до конца откорма. Установлено, что в контрольной групnе в органах и тканях выявлены дистрофические процессы, которые в последующем повлекут за собой системнье сбои и каскадные «отключения» целых систем в организме кроликов. Гистологические исследования показали, что применение комплексного пробиотического препарата в использованной дозировке оказывает положительное влияние на структурную организацию внутренних органов и длиннейшей мышцы спины и предотвращает развитие дистрофических и патологических процессов у поголовья молодняка кроликов.

Ключевые слова: кролики, пробиотический nреnарат, гистоморфологическая оценка, внутренние органы

To increase meat productivity of animals, various probiotic complexes, which have a stimulating effect on animal's body, as well as participate in the processes of normalization of intestinal microbiocenosis and increase the resistance of the organism of farm animals are widely used. The aim of the study was to investigate the effect of probiotic complex additive on the base of "Vetom 3.0" 
and "Vetom 1.1" on histological features of gastrointestinal tract and the longest back muscle of rabbits' young growth. The influence of complex probiotic additive on histological structure of organs and tissues of young rabbits was studied. The studies were conducted on cross-breed rabbits. The groups were formed from clinically healthy animals at the age of 45 days, numbering 15 heads. The animals of the first group received the main diet (feed based on cereals, cake and meal of the sublanum, wheat bran). The individuals of the second group in addition to the main diet received a complex probiotic preparation based on "Vetom 3.0" and "Vetom 1.1" at the dosage of $70 \mathrm{mg} / \mathrm{kg}$ body weight before morning feeding for 10 days in a cycle every 30 days until the end of fattening. It was found out that in the control group in the organs and tissues dystrophic processes were revealed that would eventually lead to systemic failures and cascading "disconnections" of entire systems in the body of rabbits. Histological studies showed that the use of complex probiotic preparation in fed down dosage had a positive effect on structural organization of internal organs and the longest back muscle and prevented the development of dystrophic and pathological processes of rabbits' young growth.

Keywords: rabbits, probiotic preparation, histomorphological assessment, internal.

Введение. Среди всего многообразия пробиотических препаратов интерес вызывают добавки, полученные на основе бактерий рода Bacillus [1, 2], в том числе препараты серии «Ветом», оказывающие стимулирующее действие на организм животного, а также нормализацию микробиоценоза кишечника $[3,4]$.

В наших исследованиях был использован комплексный пробиотический препарат на основе коммерческих препаратов, выпускаемых ООО НПФ «Исследовательский центр» (Россия, Новосибирская область, наукоград Кольцово) «Ветом 3.0» и «Ветом 1.1» в суммарной дозировке 70 мг/кг живого веса в соотношении 1:1.

Цель исследований. Оценка эффективности влияния пробиотической добавки «Ветом 3.0» на гистологические особенности желудочно-кишечного тракта и длиннейшей мышцы спины молодняка кроликов.
Материалы и методы. Научнохозяйственный опыт проводили в условиях частного хозяйства «О.В. Кузнецова» Воронежской области в 2017-2018 гг. В качестве объектов исследования использовали помесное поголовье кроликов (СШхНК) в возрасте 45 суток, которые были сформированы в контрольную и опытную группы по 15 голов методом параналогов из клинически здоровых животных. Кормление животных осуществляли комбикормом ПЗК-92 (производитель АО «ВЭКЗ», г. Воронеж). Кроликов первой (контрольной группы) кормили только комбикормом, а в рацион опытной (второй) группы дополнительно вводили комплексный препарат на основе коммерческих препаратов «Ветом 3.0» в дозировке 35 мг и «Ветом 1.1» в дозировке 35 мг на 1 кг веса. Доступ к воде кроликов всех групп был свободным.

Гистологические исследования тканей кроликов проводили по методу $[5,6]$. Микроскопию производили на световом микроскопе «Биомед5» (Россия).

Результаты исследований и их обсуждение. При выращивании молодняка использование пробиотических комплексов способствует нормальному развитию органов пищеварения и их своевременное использование предотвращает развитие патологических процессов [7]. В наших исследованиях представлена оценка гистоморфологической картины внутренних органов и мышечной ткани длиннейшей мышцы спины при применении пробиотического препарата «Ветом 3.0» и комплексного пробиотического препарата на основе препаратов «Ветом 3.0» и «Ветом1.1» в составе рациона кроликов. Пробиотики кролики получали путем растворе-

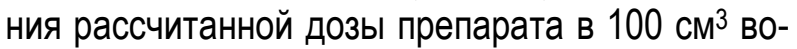
ды перед утренним кормлением курсом 10 дней каждые 30 суток.

Желудок от кроликов опытной группы имел нормальное гистологическое строение для данного вида животных. Эрозивность дна отсутствовала. Поверхность слизистой желудка была представлена однослойным призматическим эпителием по всей поверхности. Выявлено умеренное количество слизи, вырабатываемой столбчатым эпителием (рис. 1). 


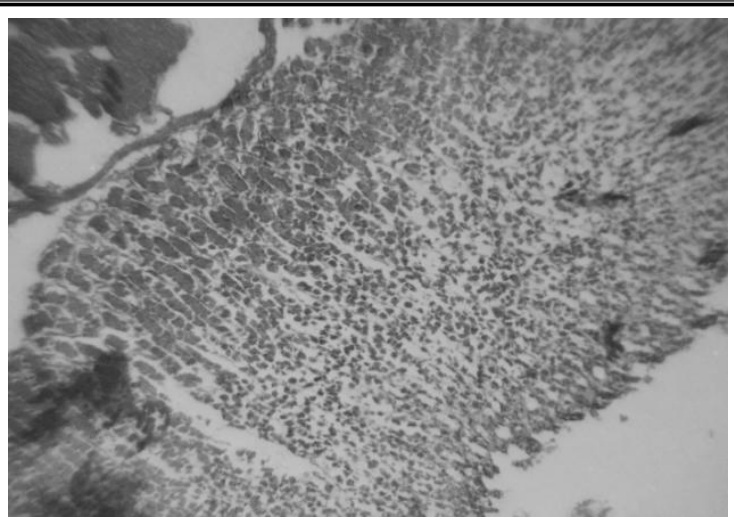

a

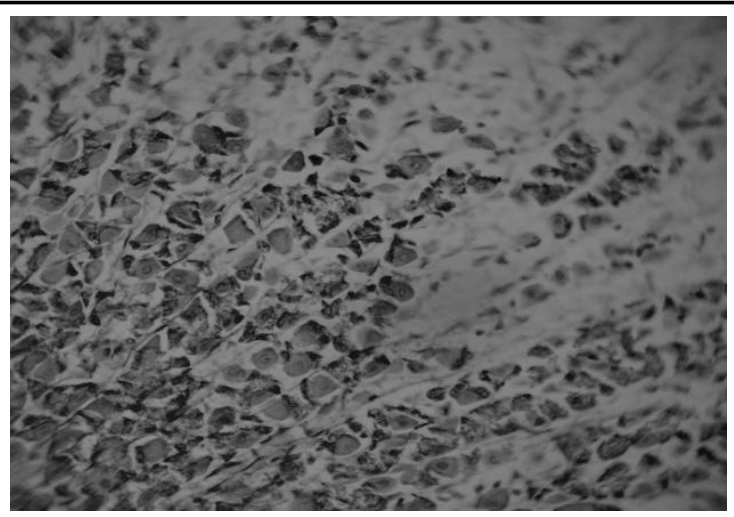

6

Pис. 1. Гистоморфологическая картина желудка кроликов (второй группы). Окуляр 10 × объектив 10(а), × обьектив 40(б)

Клетки тела и дна желез окрашены базофильно более выраженно, чем выводные протоки. Клетки фунндальных желез расположены в виде непрерывных тяжей, плотно прилегают друг к другу. Ядра занимали центральное расположение в клетках и имели округлую форму (рис.1).

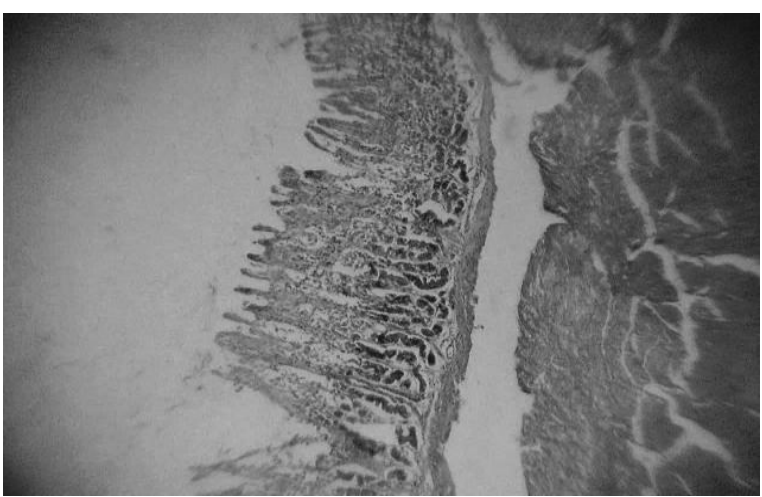

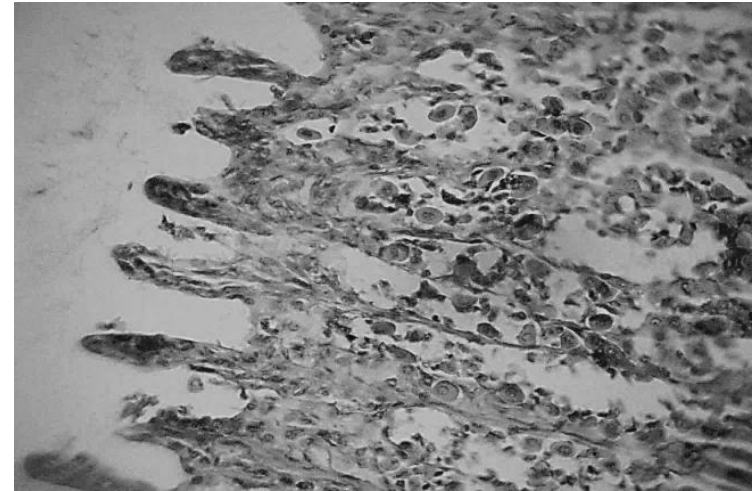

6

Puc. 2. Гистоморфологическая картина желудка кроликов (первой группы).Окуляр 10 × объектив 10(a), х обьектив 40(б)

Желудок в контрольной группе животных (рис. 2) имел нормальное гистологическое строение. Признаки вакуолизации и дистрофии выявлены в единичных клетках. Местами ядра клеток железистого эпителия располагались эксцентрично.

При гистоморфологической оценке печени второй группы обнаружено радиальное расположение балок.

Гепатоциты формируют тяжи, плотно прилегающие друг к другу. Ядра клеток выражены, без патологических изменений. В полях зрения обнаружены двуядерные гепатоциты. Сосудистое русло органа кровенаполнено (рис. 3).
В контрольной группе гистоструктура печени сохранена. Клеточные тяжи лучисто расходятся от центральной вены.

Однако в клетках печени обнаружены дистрофические изменения (как в цитоплазме, так и в ядре ядерного аппарата). Под капсулой органа в гепатоцитах присутствуют оксифильные мелкие зерна, которые также в свою очередь негативно влияют на ядерный аппарат клеток (рис. 4).

В почках у кроликов, получавших пробиотический препарат, наблюдалось полнокровие органа, четкое разделение на корковый и мозговой слои (рис. 5). 


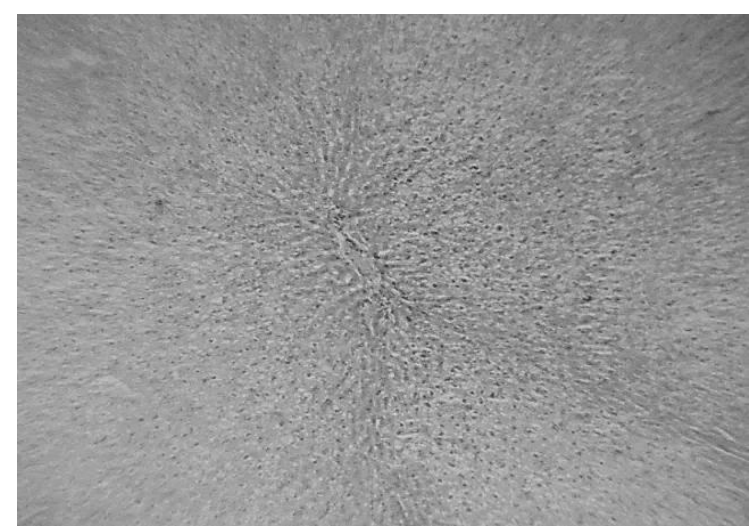

a

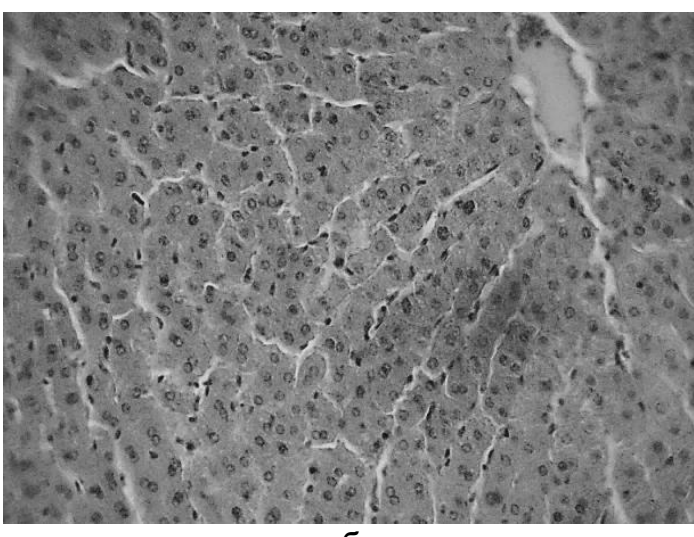

6

Puс. 3. Гистоморфологическая картина печени кроликов (вторая групnа). Окуляр 10 × объектив 10(а), × обьектив 40(б)

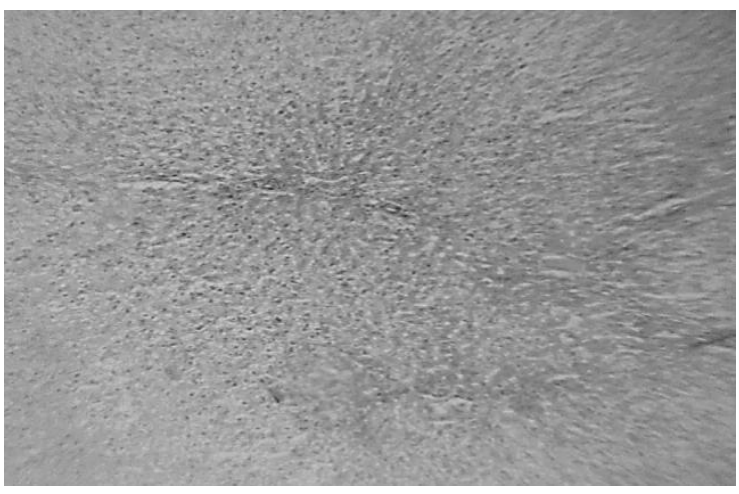

a

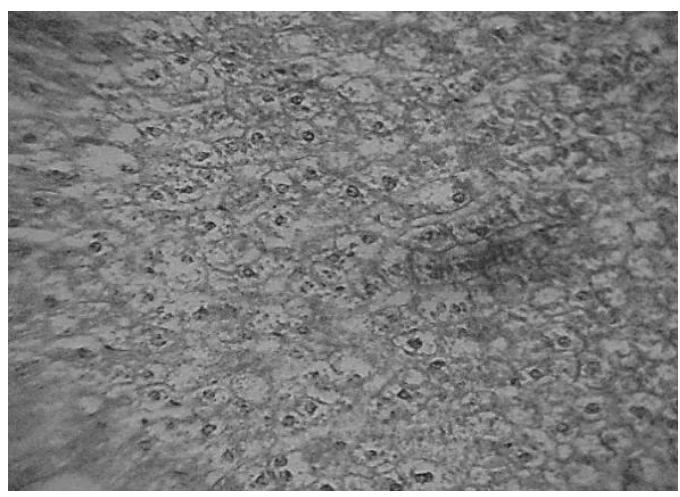

$\sigma$

Puc. 4. Гистоморфологическая картина печени кроликов (первая групnа). Окуляр 10 × объектив 10(а), х обьектив 40(б)

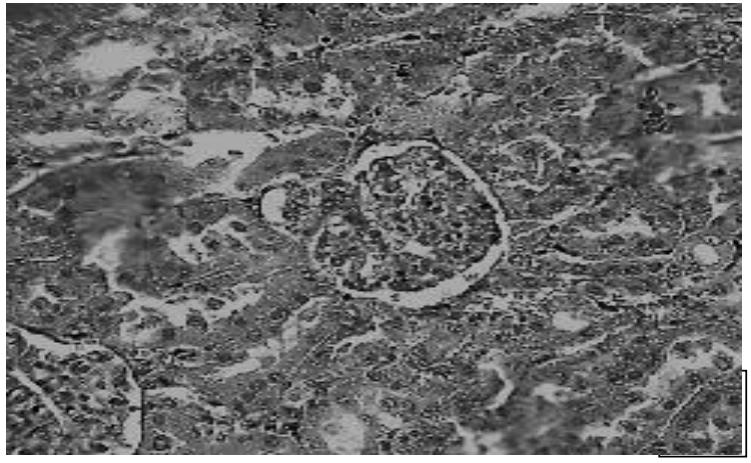

a

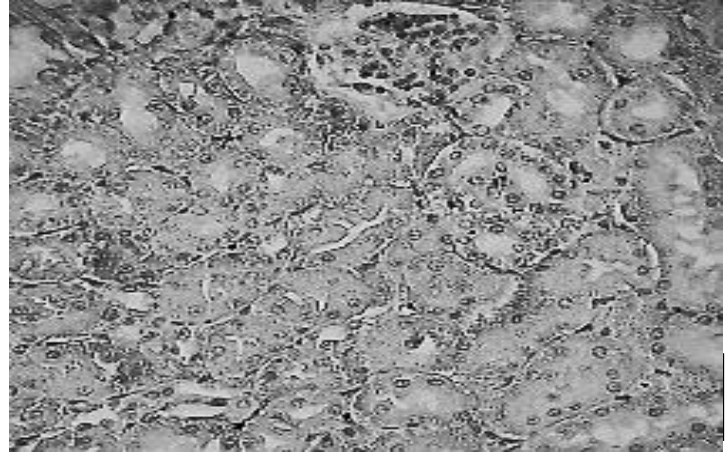

6

Puc. 5. Гистоморфологическая картина почки кроликов (вторая групnа). Окуляр 10 × объектив 10(а), х обьектив 40(б) 
В корковом слое располагались почечные тельца правильной округлой формы, местами в них была незначительно утолщена капсула Боумена-Шумлянского.

В контрольной группе у животных в почках наблюдалось незначительное утолщение кап- сулы органа (рис. 6). Границы коркового и мозгового слоев выражены незначительно. Часть извитых канальцев находилась в деформированном состоянии, сдавлена.

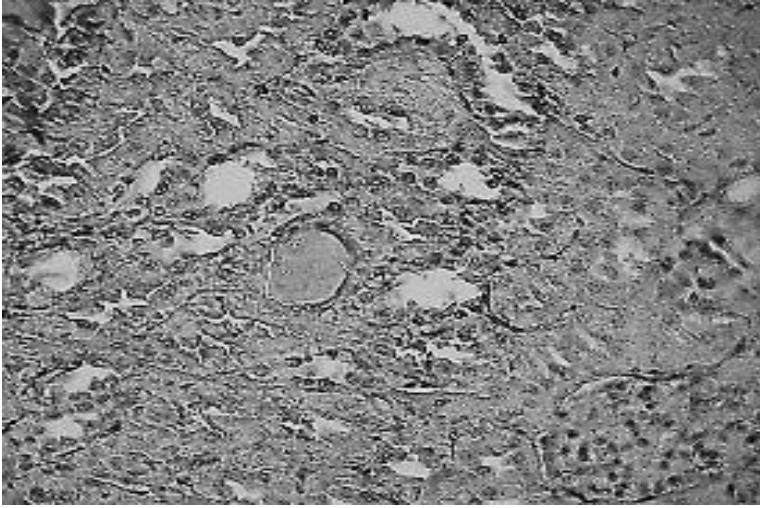

a

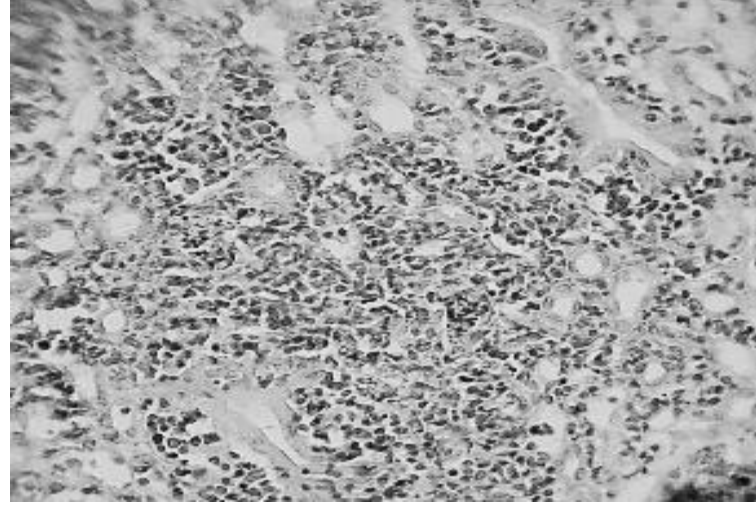

б

Puc. 6. Гистоморфологическая картина почки кроликов (первая групnа ). Окуляр 10 × объектив 10(а), х обьектив 40(б)

Со стороны ядерного аппарата выстилающего эпителия наблюдался кариолизис. Сосудистое русло паренхимы органа кровенаполнено, выявлено очаговое кровоизлияние в паренхиму.

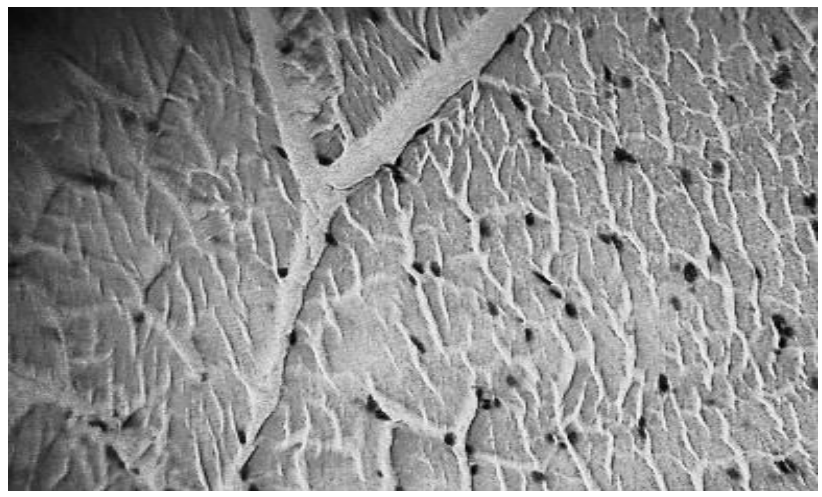

a
В корковом слое выявлены клетки соединительнотканного происхождения (рис. 6).

Гистологическое строение мышц кроликов опытной группы характеризовалось классическим строением для данной ткани (рис. 7).

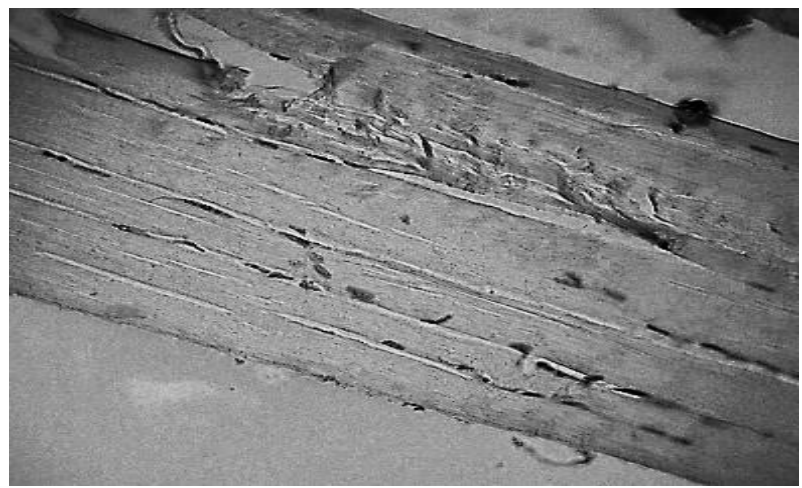

$\sigma$

Puс. 7. Гистологическое строение мыши (вторая групnа ).

Окуляр 10 × объектив 10(а), х обьектив 40(б)

На гистологическом препарате видна явная поперечная исчерченность, ядра смещены на перифрерию, деструктивные изменения отсутствуют. Выражено кровенаполнение (рис. 7). В мышечной ткани животных контрольной группы наблюдался незначительный отек, а также набухание мышечных волокон, местами волокна были разорваны и имели разную интенсивность окраски. Рисунок поперечной исчерченности сглажен. Местами выявлены диструктивные изменеия мышечного волокна (рис. 8). 


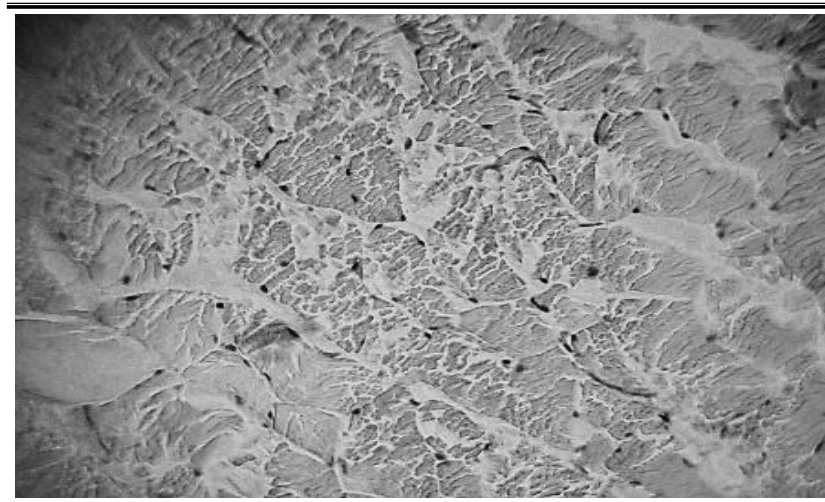

a

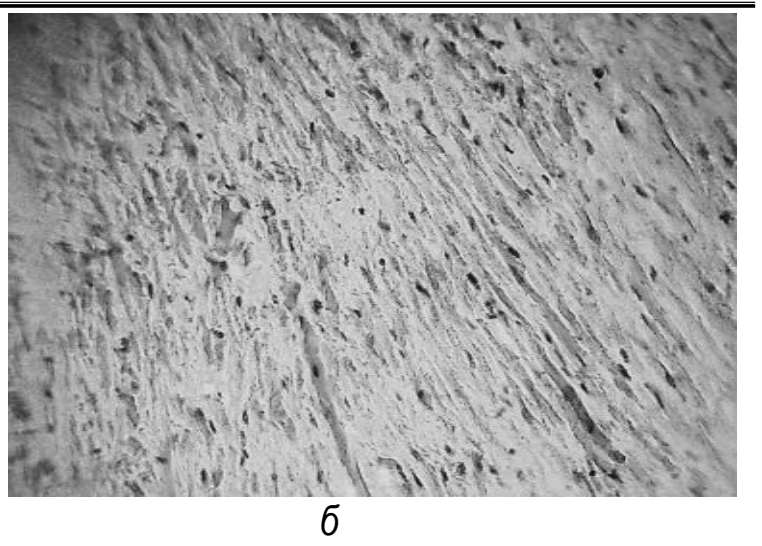

б

Puc. 8. Гистологическое строение мыши (первая групnа ).

Окуляр $10 \times$ объектив 10(а), х обьектив 40(б)

В контрольной группе в органах и тканях выявлны дистрофические процессы, которые в последующим повлекут за собой системные сбои и каскадные «отключения» целых систем в организме кроликов.

Выводы. Приведенные экспериментальные исследования показали, что применение комплексного пробиотического препарата на основе «Ветом 3.0» и «Ветом 1.1» в суммарной дозировке 70 мг/кг живой массы при откорме молодняка кроликов оказывает положительное влияние на структурную организацию органов. Таким образом, препарат благотворно влияет на продукты обмена веществ и предотвращает развитие дистрофических процессов.

\section{Литература}

1. Sandeepa M.G. and Ammani K. Effect of probiotic bacterium on growth and biochemical parameters of shrimp litopenaeusvannamei // International Journal of Recent Scientific Research Research. - 2015. - V. 6, Issue 2. P. 2871-2875.

2. Sarat Chandra M., Mahender M. [et al.]. Productive performance of broiler rabbits fed diets supplemented with probiotic and enzymes under two systems of housing // Indian J. Anim. Res. - 2014. - № 48 (4). - P. 355-361. DOI: 10.5958/0976-0555.2014.00455.5.

3. Bhatt R.S., Agrawal A.R., Sahoo A. Effect of probiotic supplementation on growth performance, nutrient utilization and carcass characteristics of growing Chinchilla rabbits// Journal of Applied Animal Research. - 2017. -
№ 45(1). - P. 304. DOI: 10.1080/09712119. 2016.1174126.

4. Laura M. Burshakbayeva, Yessenbay $I$. Islamov [et al.] The Influence of the Probiotic "Rescue Kit" On the growth and development of accelerated rabbit youngsters under the conditions of Northern Kazakhstan // Research Journal of Pharmaceutical, Biological and Chemical Sciences. - 2016. - № 7(3). P. 1575-1585.

5. Донкова Н.В. Оценка безопасности мяса цыплят-бройлеров на основе микроструктурного анализа // Вестник КрасГАУ. 2018. - № 2. - С. 33-40.

6. Структурная организация паренхиматозных органов и экспрессия цитохромов p450y крыс при применении колистина / E.B. Muхайлов, О.Ю. Фоменко, Г.А. Востроилова [и др.] // Ветеринарный фармакологический вестник. - 2018. - № 2. - С. 42-48.

7. Методы морфологических исследований / С.М. Сулейманов [и др.] / ГНУ ВНИВИПФиТ. - 2-е изд., исправ. и доп. - Воронеж, 2007. $87 \mathrm{c}$.

\section{Literatura}

1. Sandeepa M.G. and Ammani K. Effect of probiotic bacterium on growth and biochemical parameters of shrimp litopenaeusvannamei // International Journal of Recent Scientific Research Research. - 2015. - V. 6, Issue 2. P. 2871-2875.

2. Sarat Chandra M., Mahender M. [et al.]. Productive performance of broiler rabbits fed diets 
supplemented with probiotic and enzymes under two systems of housing // Indian J. Anim. Res. - 2014. - № 48 (4). - P. 355-361. DOI: 10.5958/0976-0555.2014.00455.5.

3. Bhatt R.S., Agrawal A.R., Sahoo A. Effect of probiotic supplementation on growth performance, nutrient utilization and carcass characteristics of growing Chinchilla rabbits // Journal of Applied Animal Research. - 2017. № 45(1). - P. 304. DOI: 10.1080/09712119. 2016.1174126.

4. Laura M. Burshakbayeva, Yessenbay I Islamov [et al.] The Influence of the Probiotic "Rescue Kit" On the growth and development of accelerated rabbit youngsters under the conditions of Northern Kazakhstan // Research
Journal of Pharmaceutical, Biological and Chemical Sciences. - 2016. - № 7(3). P. 1575-1585.

5. Donkova N.V. Ocenka bezopasnosti mjasa cypljat-brojlerov na osnove mikrostrukturnogo analiza // Vestnik KrasGAU. - 2018. - № 2. S. 33-40.

6. Strukturnaja organizacija parenhimatoznyh organov i jekspressija citohromov r450u krys pri primenenii kolistina / E.V. Mihajlov, O.Ju. Fomenko, G.A. Vostroilova [i dr.] // Veterinarnyj farmakologicheskij vestnik. 2018. - № 2. - S. 42-48.

7. Metody morfologicheskih issledovanij / S.M. Sulejmanov [i dr.] / GNU VNIVIPFiT. 2-e izd., isprav. i dop. - Voronezh, 2007. - 87 s. 